\title{
Skull base metastasis from papillary thyroid carcinoma: a report of three cases
}

This article was published in the following Dove Press journal:

International Medical Case Reports Journal

25 June 2015

Number of times this article has been viewed

\author{
Mutahir A Tunio' \\ Mushabbab Al Asiri \\ Khalid Hussain Al-Qahtani ${ }^{3}$ \\ Sadiq Aldandan ${ }^{4}$ \\ Khalid Riaz ${ }^{5}$ \\ Yasser Bayoumi ${ }^{6}$ \\ 'Radiation Oncology, King Fahad \\ Medical City, Riyadh, Saudi Arabia; \\ ${ }^{2}$ Radiation Oncology, Comprehensive \\ Cancer Center, King Fahad \\ Medical City, Riyadh, Saudi Arabia; \\ ${ }^{3}$ Department of Otolaryngology - \\ Head and Neck Surgery, College \\ of Medicine, King Saud University, \\ Riyadh, Saudi Arabia; ${ }^{4}$ Department \\ of Histopathology, Comprehensive \\ Cancer Center, King Fahad Medical \\ City, Riyadh, Saudi Arabia; ${ }^{5}$ Radiation \\ Oncology, Comprehensive Cancer \\ Center, King Fahad Medical City, \\ Riyadh, Saudi Arabia; ${ }^{6}$ Radiation \\ Oncology, National Cancer Institute, \\ Cairo University, Cairo, Egypt
}

\begin{abstract}
Skull base metastasis from differentiated thyroid carcinoma, including papillary and follicular thyroid carcinoma, is a rare manifestation. Herein, we present three cases of skull base metastasis of papillary thyroid carcinoma. The mean age of the patients was 68.6 (65-74) years, and the mean interval between initial diagnosis and skull base metastasis was 56.3 (28-89) months. Cranial nerve palsies were seen in all patients. Intensity modulated radiation therapy to deliver 6,000-6,600 cGy to the skull base metastasis was given to all patients, in addition to partial resection in one patient. At the time of last follow-up, all skull base metastases were well controlled.
\end{abstract}

Keywords: papillary thyroid carcinoma, skull base metastasis, treatment

\section{Introduction}

Differentiated thyroid carcinoma, especially papillary thyroid carcinoma (PTC), commonly metastasizes to the regional lymph nodes, lungs, and bone. However, the brain is an uncommon site of metastasis, being found only in $0.15 \%-1.3 \%$ of cases. ${ }^{1}$ Moreover; cerebellar metastases from PTC are exceptionally rare, with only 13 reported cases of cerebellar metastasis from PTC having been published so far. ${ }^{2}$ Herein, we describe and discuss the signs and symptoms, diagnostic work-up, differential diagnosis, and management in three cases of cerebellar metastasis from PTC.

\section{Case I}

A 74-year-old female with a diagnosis of PTC, tall cell variant (pT3N1aM0), underwent total thyroidectomy, followed by radioactive iodine ablation $(150 \mathrm{mCi})$ in February 2009. The patient was taking L-thyroxine $125 \mu \mathrm{g}$ as thyroid replacement therapy, and remained in complete remission until June 2013, when she presented with a 3-month history of left upper neck pain. A pertinent neurological finding was ipsilateral cranial nerve XII palsy. Serum thyroglobulin levels were elevated $(245.6 \mu \mathrm{g} / \mathrm{L})$. No focus of abnormal tracer uptake was seen on I-131 whole body scintigraphy. Magnetic resonance imaging of the brain revealed an enhancing mass involving the left side of the clivus and the left occipital condyle (Figure 1). 18-Fluorodeoxyglucose positron emission tomography-computed tomography (CT) showed intense hypermetabolic activity (standardized uptake volume 138), corresponding to the destructive mass involving the clivus and left occipital condyle (Figure 2). A punch biopsy was taken from the clivus via the transnasal-transsphenoidal approach. Histopathology of the biopsy revealed tall papillary cells (height at least two or three times their width) mixed with small
Correspondence: Mutahir A Tunio Radiation Oncology, Comprehensive Cancer Center, King Fahad Medical City, Riyadh 59046, Saudi Arabia

Tel +966 II 2889999

Fax +966 || 2889999

Email drmutahirtonio@hotmail.com
International Medical Case Reports Journal 20|5:8 |27-|3| (c) (i) (9) 2015 Tunio et al. This work is published by Dove Medical Press Limited, and licensed under Creative Commons Attribution - Non Commercial (unported, v3.0) License. The full terms of the License are available at http://creativecommons.org/licenses/by-nc/3.0/. Non-commercial uses of the work are permitted without any further permission fove Medical Press Limited, provided the work is properly attributed. Permissions beyond the scope of the License are administered by Dove Medical Press Limited. Information on how to request permission may be found at: http://www.dovepress.com/permissions.php 


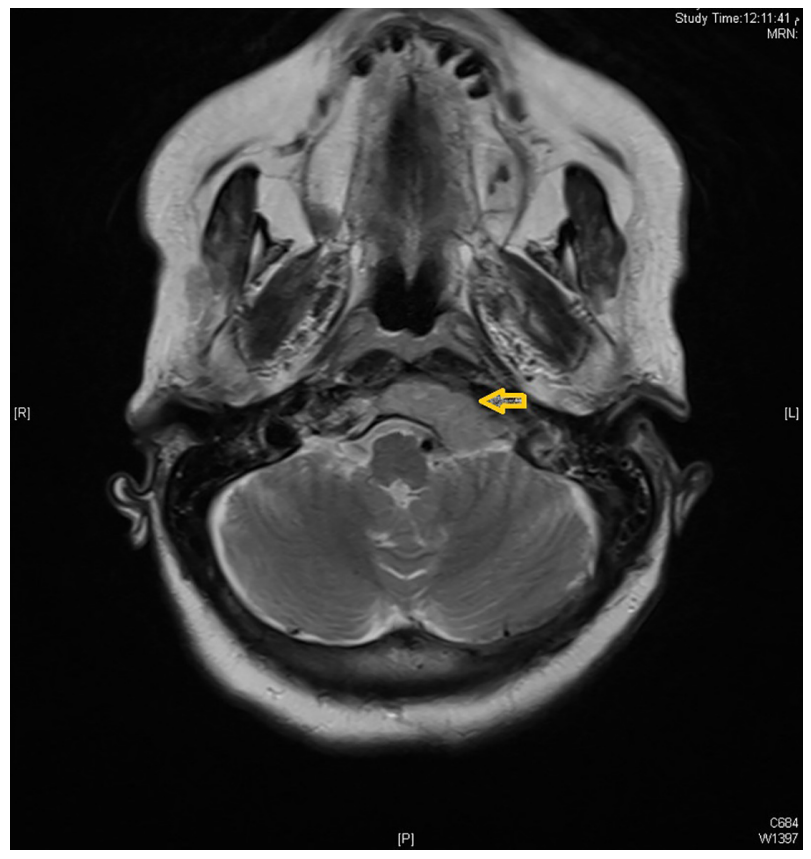

Figure I Case I: Axial view magnetic resonance imaging brain showing mass involving the left side of the clivus and left occipital condyle. The yellow arrow shows the mass involving the left side of the clivus and occipital condyle.

fragments of bone, and immunopositivity for thyroid transcription factor- 1 and cytokeratin 19 confirmed the diagnosis of metastatic tall cell variant PTC (Figure 3). The patient was treated with external beam irradiation via intensity modulated radiotherapy (IMRT). A total dose of 6,600 cGy was delivered to the tumor in 33 fractions over 6.5 weeks. The treatment course was completed without any significant acute toxicity. Follow-up has been undertaken for 18 months, and the patient has remained clinically asymptomatic without any evidence of recurrence or distant metastases.

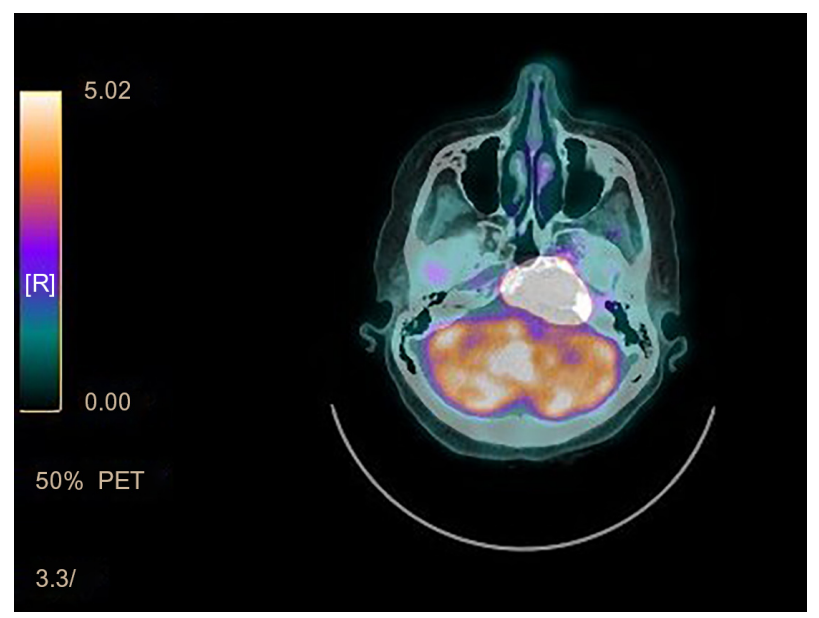

Figure 2 Case I: PET/CT showing intense hypermetabolic activity (standardized uptake volume 138), corresponding to the destructive mass involving the left clivus and left occipital condyle.

Abbreviations: CT, computed tomography; PET, positron emission tomography.

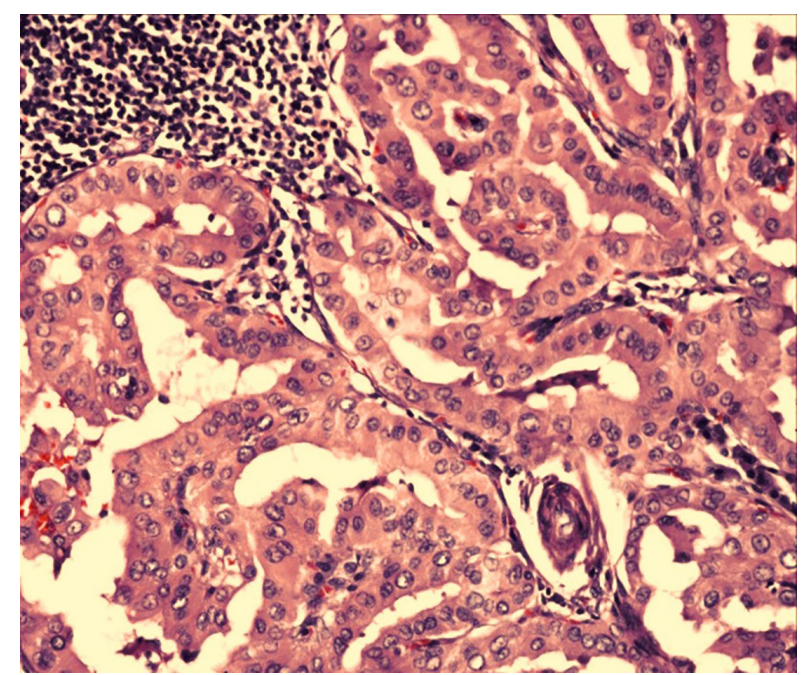

Figure 3 Case I: Hematoxylin-eosin staining showing tall papillary cells (height at least two to three times their width) thyroid carcinoma.

\section{Case 2}

A 67-year-old female with a diagnosis of PTC insular variant (pT4N1bM0) underwent total thyroidectomy and neck dissection in April 2011. After surgery, she was treated with radioactive iodine $(150 \mathrm{mCi})$ and thyroid bed irradiation via IMRT with a dose of 66 Gy in 33 fractions, In September 2011, she developed lung metastasis, and was treated with a second radioactive iodine ablation dose (200 $\mathrm{mCi}$ ). In August 2013, she started to complain of headache, diplopia, and facial weakness. Neurological findings were cranial nerve II, III, and V palsies on the left side. Serum thyroglobulin levels were found to be raised $(3,200 \mu \mathrm{g} / \mathrm{L})$. Whole body scintigraphy showed intense foci of uptake in the skull base and in both lungs. CT brain revealed an infiltrative enhancing mass occupying the right cavernous sinus and extending to the pituitary fossa and clivus (Figure 4A and B). Histopathological examination of a transnasal-transsphenoidal biopsied lesion revealed islands of small uniform cells, areas of tumor necrosis, and microfollicles with thyroglobulin, which confirmed the diagnosis of metastatic PTC, insular variant (Figure 5). The lesion was treated with IMRT, and a total dose of 6,000 cGy in 30 fractions was delivered to the tumor over 6 weeks without any significant acute toxicity. After completion of IMRT, the patient was given a third radioactive iodine ablation dose $(150 \mathrm{mCi})$. At 14 months of follow-up, the patient was alive with progressive in disease in the lungs, an elevated thyroglobulin level $(5,000 \mu \mathrm{g} / \mathrm{L})$, and a stable skull base lesion.

\section{Case 3}

A 65-year-old male underwent total thyroidectomy for multifocal PTC, follicular variant (pT3N1M0), followed 

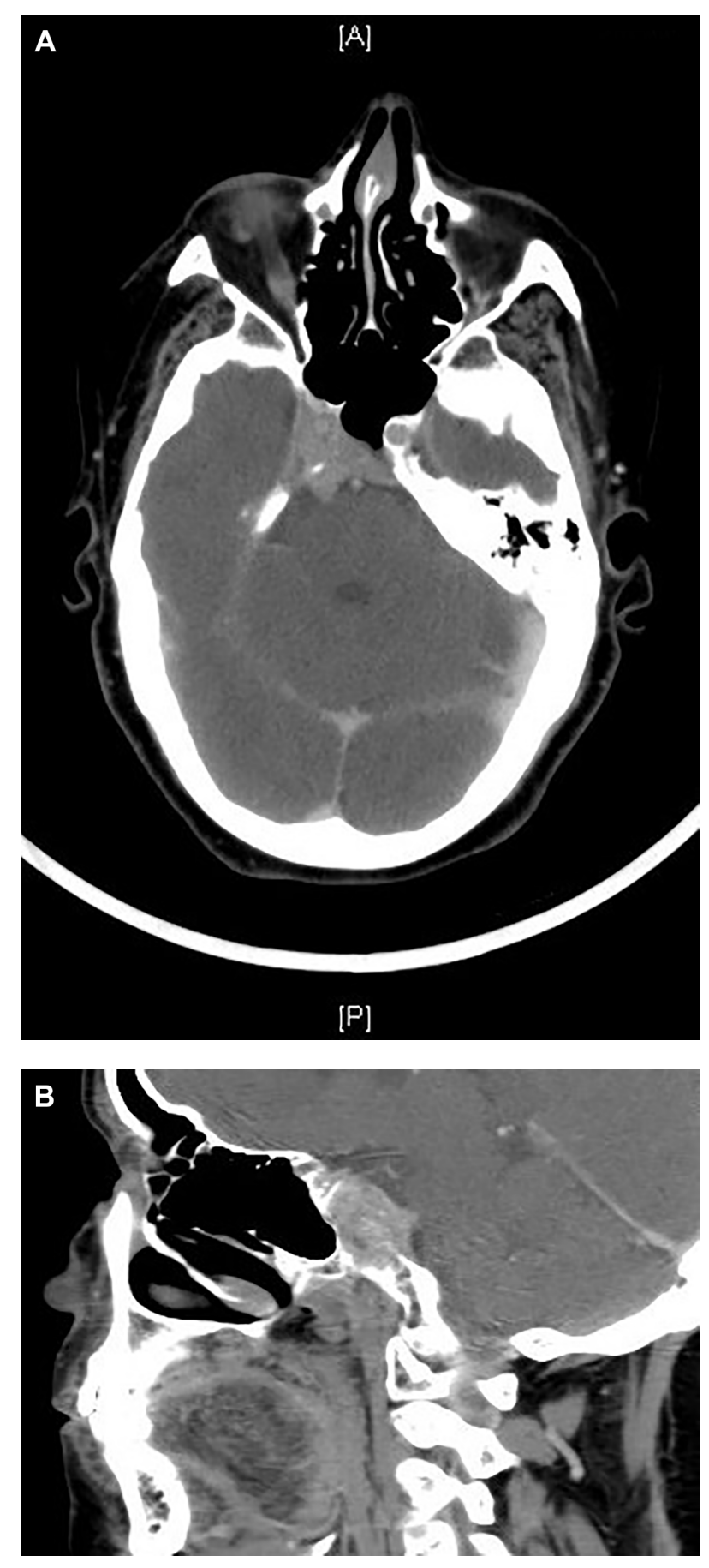

Figure 4 Case 2: (A) Axial and (B) sagittal views on computed tomography brain showing an infiltrative enhancing mass occupying the right cavernous sinus extending to the pituitary fossa and clivus.

by radioactive iodine ablation $(150 \mathrm{mCi})$ in July 2006 . The patient was on thyroid replacement therapy with L-thyroxine $150 \mu \mathrm{g}$, and was in complete remission until December 2013, when he presented with a 2-month history of headache, dysphagia, hoarseness, dysarthria, and hearing impairment. Pertinent neurological findings were cranial nerve IX, X, XI, and XII palsies on the left side (Collet-Sicard syndrome)

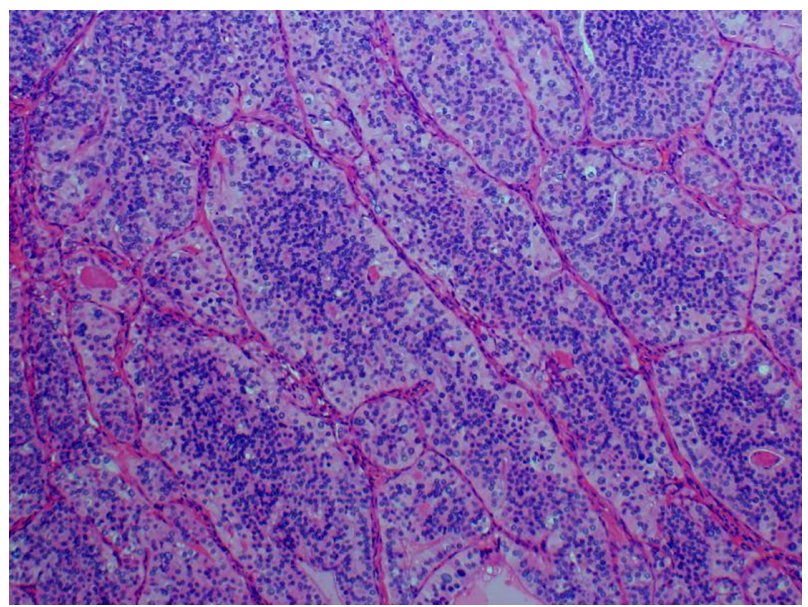

Figure 5 Case 2: Hematoxylin-eosin staining showing islands of small uniform cells, areas of tumor necrosis, and microfollicles.

with moderate sensorineural hearing loss and $100 \%$ word recognition on the affected side. Serum thyroglobulin levels were found to be elevated $(46 \mu \mathrm{g} / \mathrm{L})$. CT/magnetic resonance imaging brain revealed a large infiltrative mass involving the petrous, tympanic, and mastoid parts of the left temporal bone with intracranial extension. There was also evidence of invasion of the left sigmoid sinus, left internal jugular vein, and left internal auditory canal (Figure 6). The patient

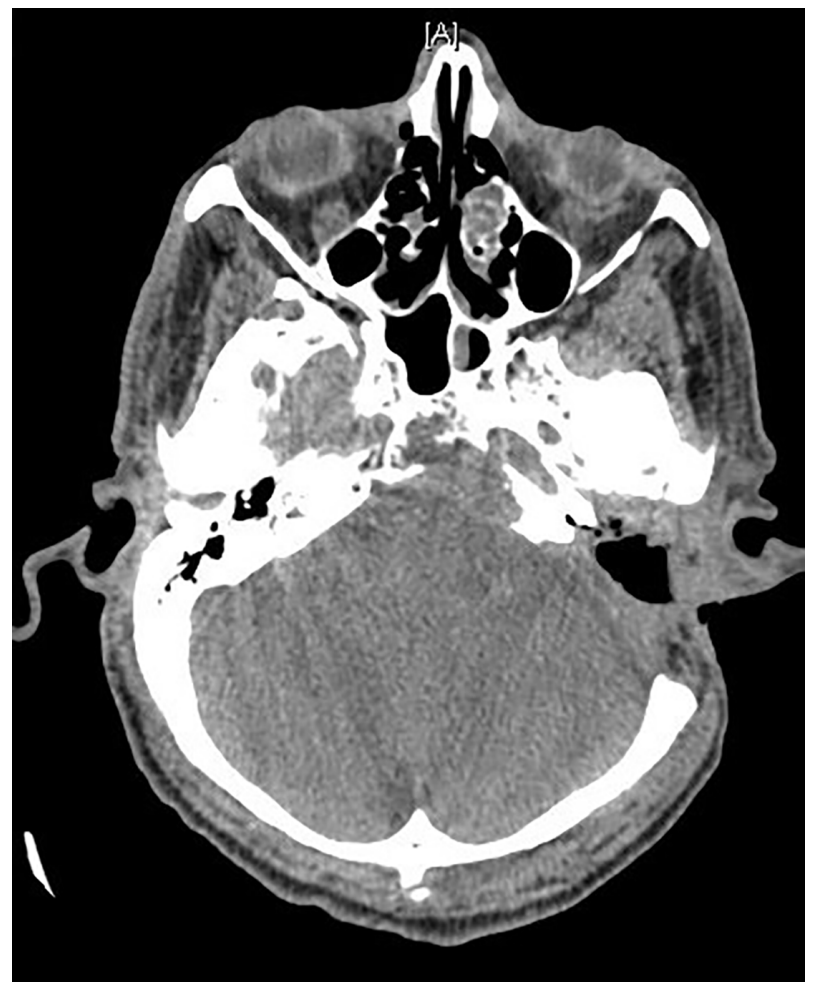

Figure 6 Case 3: Computed tomography brain showing a large infiltrative mass involving the petrous, tympanic, and mastoid parts of the left temporal bone with intracranial extension. 


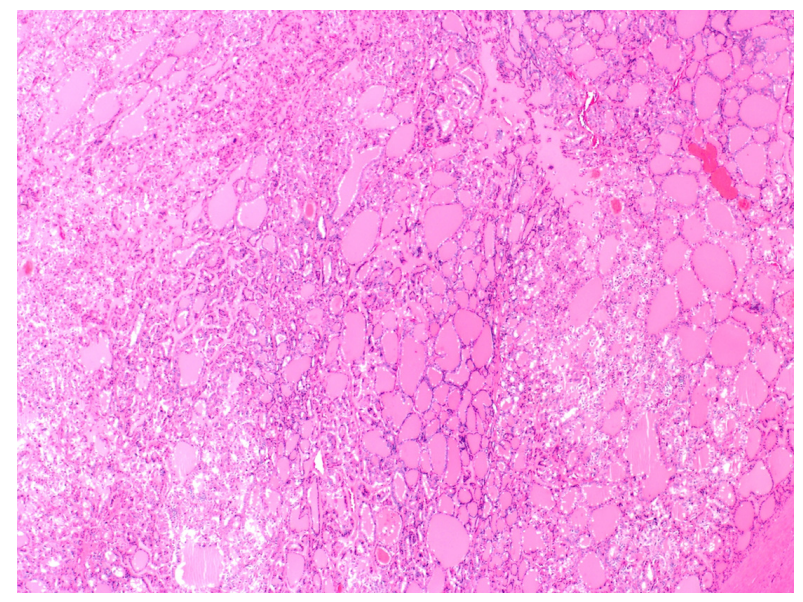

Figure 7 Case 3: Follicular pattern of papillary thyroid carcinoma.

underwent left retromastoidal suboccipital craniotomy, with partial resection of the lesion. Histopathological examination confirmed the diagnosis of metastatic PTC, follicular variant (Figure 7). Following surgery, the residual tumor was treated with IMRT, using a total dose of 6,000 cGy in 30 fractions. After 12 months of follow-up, the patient remained well without any signs of progression or treatmentrelated complications.

\section{Discussion}

Skull base metastasis (SBM) of differentiated thyroid carcinoma shows a predominance of follicular thyroid carcinoma
(FTC), because FTC is more prone to spread via the hematogenous route to the lungs and bone. ${ }^{2}$ However, SBM from PTC is rare. To date, only ten cases of SBM from PTC have been reported (Table 1). ${ }^{3-11}$ In agreement with the reported cases, SBM in our series were seen in the sixth and seventh decades of life, at a mean age of 68.6 (range 65-74) years, and the mean interval between initial diagnosis and SBM was 56.3 (range $28-89$ ) years. ${ }^{3,8}$ In our series, two patients with aggressive variants of PTC (tall cell and insular) were recognized. According to the recent literature, these aggressive variants have a worse prognosis than classic PTC, and patients with these variants should be treated aggressively with thyroidectomy, neck dissection, and radioactive iodine, regardless of tumor size. ${ }^{12}$

The most common symptoms of SBM from PTC in our series were headache and cranial nerve palsies, which is in agreement with reports in the literature. ${ }^{11,12}$ However, a rare presentation of Collet-Sicard syndrome (cranial nerve IX, X, XI, and XII palsies) was also described, which is the first reported case in SBM from PTC. ${ }^{13}$ Diagnosis of SBM is challenging, because these lesions are often mistaken for chordoma, chondrosarcoma, meningioma, or schwannoma on CT and magnetic resonance imaging. ${ }^{14}$ Biopsies should be performed in such cases for definitive diagnosis. In our series, a biopsy was taken via the transnasal-transsphenoidal approach in two patients.

Treatment of SBM is challenging. Complete surgical resection is often difficult because of the presence of

Table I Previously published cases with skull base metastasis from papillary thyroid carcinoma

\begin{tabular}{|c|c|c|c|c|c|}
\hline Reference & Age (years)/sex & Symptoms & Site & Histopathology & Treatment \\
\hline Matsuno et al $\left.\right|^{3}$ & $56 / F$ & $\begin{array}{l}\text { Blurred vision, III, VI } \\
\mathrm{CN} \text { palsy }\end{array}$ & Sella turcica, sphenoid sinus & PTC, classic & $\begin{array}{l}\text { TSH suppression, } \\
\text { RAI }\end{array}$ \\
\hline Bell et $\mathrm{al}^{4}$ & $35 / F$ & $\begin{array}{l}\text { Hemianopsia, DI, } \\
\text { amenorrhea }\end{array}$ & Sella turcica, pituitary gland & PTC, classic & $\begin{array}{l}\text { Transsphenoidal } \\
\text { surgery }\end{array}$ \\
\hline Sziklas et $\mathrm{a}^{5}$ & $44 / M$ & $\begin{array}{l}\text { Panhypopituitarism, } \\
\text { hypogonadism }\end{array}$ & Sella turcica, pituitary gland & PTC, classic & $\begin{array}{l}\text { Transsphenoidal } \\
\text { surgery, RAI }\end{array}$ \\
\hline Takami et al ${ }^{6}$ & $4 I / M$ & $\begin{array}{l}\text { Diplopia, subarachnoid } \\
\text { hemorrhage }\end{array}$ & Cavernous sinus, cerebellopontine angle & PTC, classic & $\begin{array}{l}\text { Surgery and gamma } \\
\text { knife radiosurgery }\end{array}$ \\
\hline Freeman et $\mathrm{al}^{7}$ & $50 / M$ & Horner's syndrome & Sphenoid sinus & PTC, classic & Surgery, RAI, RT \\
\hline Masiukiewicz & I. $56 / \mathrm{M}$ & I. Panhypopituitarism & I. Sella turcica, pituitary gland & PTC, classic & RAI \\
\hline et $\mathrm{a}^{8}$ & 2. $55 / \mathrm{F}$ & $\begin{array}{l}\text { 2. Panhypopituitarism, } \\
\text { blindness }\end{array}$ & 2. Sella turcica, cavernous sinus & & \\
\hline Yan et $\mathrm{al}^{9}$ & $73 / M$ & $\begin{array}{l}\text { Visual impairment, } \\
\text { diplopia, epistaxis }\end{array}$ & $\begin{array}{l}\text { Petrous bone, sella turcica, clivus, } \\
\text { pterygoid plate, ethmoid sinus, } \\
\text { infratemporal fossa, cavernous sinus }\end{array}$ & PTC, classic & Surgery, RAI \\
\hline Hugh et $\mathrm{al}^{10}$ & $64 / F$ & Incidental finding & Petrous bone & PTC, classic & Surgery, RT \\
\hline Kutluhan et al" & $61 / M$ & VI, VII, IX, X CN palsy & Temporooccipital bone & PTC, classic & Surgery, RT \\
\hline \multirow[t]{3}{*}{ Our series } & I. $74 / \mathrm{F}$ & I. XII CN palsy & I. Clivus, occipital condyle & I. PTC, tall cell & I. IMRT \\
\hline & 2. $67 / \mathrm{F}$ & 2. II, III, and $\vee C N$ palsy & 2. Sella turcica, pituitary, cavernous sinus & 2. PTC, insular & 2. IMRT \\
\hline & 3. $65 / M$ & $\begin{array}{l}\text { 3. Collet-Sicard } \\
\text { syndrome }\end{array}$ & $\begin{array}{l}\text { 3. Petrous, tympanic, mastoid, temporal } \\
\text { bone with intracranial extension }\end{array}$ & 3. PTC, follicular & 3. Surgery, IMRT \\
\hline
\end{tabular}

Abbreviations: F, female; M, male; CN, cranial nerve; PTC, papillary carcinoma thyroid; TSH, thyroid stimulating hormone; RAI, radioactive iodine; DI, diabetes insipidus; $\mathrm{RT}$, radiation therapy; IMRT, intensity modulated radiation therapy. 
adjacent vital structures (brainstem, cochlea, and cranial nerves), cerebrospinal fluid leak, and bleeding. In our series, one patient had safe partial resection via a transcranial "far lateral" approach, which was found in agreement with the literature. ${ }^{15}$ For unresectable and residual tumors, radiation therapy is feasible option. With the advent of novel techniques in radiation therapy (IMRT, protons, carbon ions, and stereotactic radiosurgery), it is now possible to deliver a high dose to the tumor to achieve better local control without any serious acute toxicity, as seen in our series. ${ }^{16}$

In conclusion, SBM from PTC is a rare clinical entity, and is often associated with cranial nerve dysfunction. Histopathological tissue diagnosis should always be attempted to initiate effective treatment, which relies on a multidisciplinary approach to prolong disease-free and overall survival rates.

\section{Acknowledgment}

Written consent was taken from all patients for publication of this paper.

\section{Disclosure}

No grants or funding was received for this study. The authors have no conflicts of interest in this work.

\section{References}

1. Nigam A, Singh AK, Singh SK, Singh N. Skull metastasis in papillary carcinoma of thyroid: a case report. World J Radiol. 2012;4:286-290.

2. Mydlarz WK, Wu J, Aygun N, et al. Management considerations for differentiated thyroid carcinoma presenting as a metastasis to the skull base. Laryngoscope. 2007;117:1146-1152.

3. Matsuno A, Murakami M, Hoya K, et al. Clinicopathological and molecular histochemical review of skull base metastasis from differentiated thyroid carcinoma. Acta Histochem Cytochem. 2013;46:129-136.
4. Bell CD, Kovacs K, Horvath E, Smythe H, Asa S. Papillary carcinoma of thyroid metastatic to the pituitary gland. Arch Pathol Lab Med. 2001;125:935-938.

5. Sziklas JJ, Mathews J, Spencer RP, Rosenberg RJ, Ergin MT, Bower BF. Thyroid carcinoma metastatic to pituitary. J Nucl Med. 1985;26:1097.

6. Takami T, Ohata K, Tsuyuguchi N, et al. Cavernous sinus metastasis from thyroid papillary adenocarcinoma. J Clin Neurosci. 2002;9: $598-600$.

7. Freeman JL, Gershon A, Liavaag PG, Walfish PG. Papillary thyroid carcinoma metastasizing to the sphenoid-ethmoid sinuses and skull base. Thyroid. 1996;6:59-61.

8. Masiukiewicz US, Nakchbandi IA, Stewart AF, Inzucchi SE. Papillary thyroid carcinoma metastatic to the pituitary gland. Thyroid. 1999;9: 1023-1027.

9. Yan B, Liu DG, Lu HL, Zhang QH. Images for diagnosis. Papillary thyroid microcarcinoma presenting as skull base metastasis. Chin Med $J$ (Engl). 2010;123:2750-2752.

10. Hugh SC, Enepekides D, Wong J, Yeung R, Lin VY. Metastasis of follicular variant of papillary thyroid carcinoma masquerading as primary temporal bone tumour. J Laryngol Otol. 2011;125:528-532.

11. Kutluhan A, Yalçıner G, Bozdemir K, Ozdemir E, Tarlak B, Bilgen AS. Papillary thyroid carcinoma with metastasis to the temporooccipital skull: a case report. Kulak Burun Bogaz Ihtis Derg. 2012;22: 160-163.

12. Kazaure HS, Roman SA, Sosa JA. Aggressive variants of papillary thyroid cancer: incidence, characteristics and predictors of survival among 43,738 patients. Ann Surg Oncol. 2012;19:1874-1880.

13. Opie NJ, Ur-Rehman K, James GJ. A case of Collet-Sicard syndrome presenting to the Oral and Maxillofacial Surgery Department and a review of the literature. Br J Oral Maxillofac Surg. 2010;48:9-11.

14. Neelakantan A, Rana AK. Benign and malignant diseases of the clivus. Clin Radiol. 2014;69:1295-1303.

15. Benet A, Prevedello DM, Carrau RL, et al. Comparative analysis of the transcranial "far lateral" and endoscopic endonasal "far medial" approaches: surgical anatomy and clinical illustration. World Neurosurg. 2014;81:385-396.

16. Ohta N, Suzuki Y, Hasegawa A, Aoyagi M, Kakehata S. Carbon ion beam radiotherapy for sinonasal malignant tumors invading skull base. Case Rep Otolaryngol. 2014;2014:241856.
International Medical Case Reports Journal

\section{Publish your work in this journal}

The International Medical Case Reports Journal is an international, peer-reviewed open-access journal publishing original case reports from all medical specialties. Previously unpublished medical posters are also accepted relating to any area of clinical or preclinical science. Submissions should not normally exceed 2,000 words or

\section{Dovepress}

4 published pages including figures, diagrams and references. The manuscript management system is completely online and includes a very quick and fair peer-review system, which is all easy to use. Visit http://www.dovepress.com/testimonials.php to read real quotes from published authors. 